\title{
CARACTERIZAÇÃo DAS INCLUSÓES FLUIDAS DOS TOPÁZIOS IMPERIAIS DA REGLÃo DE OURO PRETO, MG
}

\author{
A.L.Gandini ${ }^{1}$ \\ R.M.S.Bello ${ }^{2}$ \\ K.Fuzikawa ${ }^{3}$ \\ D.P.Svisero ${ }^{2}$ \\ C.M.Ferreira ${ }^{1}$
}

\section{RESUMO}

Um grande número de inclusōes fluidas de dimensōes, orientaçōes e morfologias variadas, bifásicas à temperatura de $25^{\circ} \mathrm{C}$, ocorre no topázio imperial da região de Ouro Preto.

Estudos microtermométricos desses vários tipos de inclusōes mostraram que elas săo constituídas essencialmente por soluçōes aquosas e $\mathrm{CO}_{2}$; possuem, ainda, salinidades e temperaturas mínimas de formaçăo semelhantes, quaisquer que sejam suas morfologias e orientaçōes.

Os dados obtidos sugerem que a formação das inclusôes, em cada agrupamento, foi concomitante, ou em etapas de condiçóes de P e T levemente distintas. No entanto, em grupos distintos de inclusōes fluidas, foram observadas características próprias, sugerindo uma interaçăo entre os fluidos e as rochas encaixantes. Todavia, năo deve ser descartada a influência dos eventos pós-cristalização nos fluidos originais.

\section{ABSTRACT}

Optical investigation revealed a great number of fluid inclusions in the imperial variety of topaz that occurs at several localities around Ouro Preto, Minas Gerais, Brazil. The inclusions are biphasic at $25^{\circ} \mathrm{C}$ and display several patterns of morphology,

\footnotetext{
${ }^{1}$ Departamento de Geologia, Escola de Minas, Universidade Federal de Ouro Preto, Minas Gerais.

${ }^{2}$ Departamento de Mineralogia e Petrologia, Instituto de Geociencias/USP, Săo Paulo.

${ }^{3}$ Comisslo Nacional de Energia Nuclear, Belo Horizonte.
} 
orientation, and dimensions. Microthermometric studies revealed that the inclusions are filled mainly with aqueous solutions and $\mathrm{CO}_{2}$. Moreover, for all the morphological types of inclusion, temperatures of formation are always similar. The data also suggest that all the inclusions developed simultaneously or under very similar conditions of PT. On the other hand, distinct group of inclusions display peculiar characteristics suggesting some sort of interaction between the fluids and the country rock. Finally, one should bear in mind the influence of postcrystallization events on the composition and thermodynamic properties of the original fluid inclusions.

\section{INTRODUÇÃO}

Desde a época de SORBY (1858), que estabeleceu as bases de uma geotermometria pelo aquecimento das inclusóes fluidas, a microtermometria tem sido o método especifico mais freqũentemente utilizado no estudo dessas mesmas inclusōes. Esse método consiste em determinar as temperaturas de mudanças de fase dos componentes das inclusōes quando submetidas a baixas e altas temperaturas (POTY et al., 1976; HOLLISTER \& CRAWFORD, 1981). Isso é realizado através de uma platina, adaptada a um microscópio petrográfico comum, que permite o resfriamento da amostra até $-180^{\circ} \mathrm{C}$ e seu aquecimento até $600^{\circ} \mathrm{C}$. Com os valores das temperaturas assim obtidos, podem ser determinadas as composigōes, densidades e salinidades dos fluidos e suas temperaturas e pressōes de aprisionamento, que constituirăo dados importantes para a caracterizaçấo das condiçóes físicoquímicas reinantes durante os processos de cristalizaçăo ou recristalizaçăo do mineral hospedeiro (HOLLISTER, 1981; ROEDDER, 1984; FUZIKAWA, 1985).

Observa-se, desse modo, que o estudo das inclusóes fluidas constitui ferramenta importante para a compreensáo das condiçóes de cristalizaçấo e da origem dos minerais que as contem. Por isso objetivou-se neste trabalho a caracterizaçâo dessas inclusōes quanto aos modos de ocorrencia e morfologia que, ao lado de dados microtermométricos já obtidos, poderăo permitir um melhor entendimento da genese dos topázios de Ouro Preto.

Dados microcalorimétricos preliminares das inclusoes fluidas das jazidas de Capăo do Lana e Caxambu, encontram-se em GANDINI et al. (1990). No presente trabalho são discutidos detalhadamente os aspectos morfológicos e os modos de ocorrencia das inclusōes fluidas dessas duas jazidas e de outras ocorrencias da região de Dom Bosco e Boa Vista (Fig. 1); além disso, săo apresentados dados e resultados microtermométricos adicionais sobre as inclusốes fluidas da jazida de Capão do Lana.

\section{O TOPÁZTO IMPERIAL DA REGIX̉O DE OURO PRETO}

As ocorrencias de topázio imperial da região de Ouro Preto, MG (Fig. 1), săo 


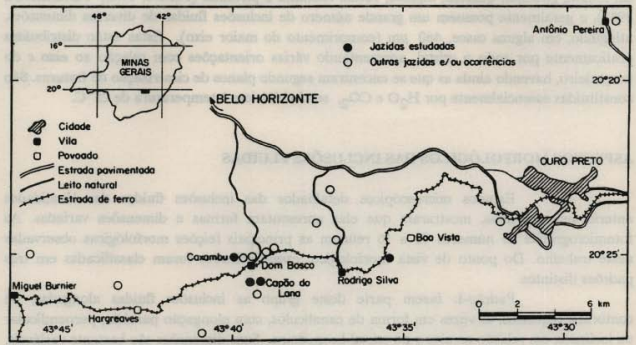

Figura 1 - Localizaçăo geográfica das jazidas de Capäo do Lana, Carambu e outras ocorréncias de topázio imperial da regilăo de Ouro Preto, MG (baseado no mapa da Prefeitura do Município de Ouro Preto, MG, 1980).

conhecidas na literatura geológica desde a segunda metade do século passado (GORCEIX, 1881). Apesar do caráter único desses depósitos, do potencial considerável verificado no decorrer desses anos, e da alta qualidade gemológica do topázio, os trabalhos focalizando a gênese săo relativamente escassos, e os poucos existentes, são controvertidos. Informaçōes gerais sobre a mineralogia e a geologia da regiăo podem ser encontradas em OLSEN (1971), PIRES (1983), KELLER (1983), FERREIRA (1983, 1987), FERREIRA (no prelo) e CASSEDANNE (1989).

O topázio imperial de Ouro Preto ocorre sob a forma de cristais prismáticos terminados, sendo raros os exemplares biterminados. Apesar de ocorrer em agregados e fragmentos, predominam os tipos idiomórficos constituídos de um prisma rómbico vertical, com dois prismas rômbicos horizontais. As dimensóes variam desde alguns milímetros ate 20 $\mathrm{cm}$ aproximadamente, predominando a faixa em torno de 1 a $5 \mathrm{~cm}$. A cor, uma das propriedades mais notáveis desses topázios varia de amarelo dourado a vermelho conhaque com tonalidades transicionais entre esses dois tipos. O topázio é extraído de uma rocha alterada de coloração castanha avermelhada escura, sem vestígios da rocha original. Relaçóes de campo sugerem que a Formaçăo Fecho do Funil do Super Grupo Minas seja a encaixante dos depósitos, mas não há dados sobre a época de formaçăo do topázio.

Esses topázios englobam algumas fases sólidas, tais como hematita, 
carbonato, goethita, quartzo, topázio, rutilo, caolinita e pirofilita (PIRES, 1983; FERREIRA, 1983), e geralmente possuem um grande número de inclusỏes fluidas de diversas dimensóes, atingindo, em alguns casos, $460 \mu \mathrm{m}$ (comprimento do maior eixo). Estas estáo distribuídas praticamente por todo o cristal, apresentando várias orientaçóes com relaçáo ao eixo c do hospedeiro, havendo ainda as que se encontram segundo planos de cicatrizaçáo de fraturas. São constituídas essencialmente por $\mathrm{H}_{2} \mathrm{O}$ e $\mathrm{CO}_{2}$, sendo bifásicas à temperatura de $25^{\circ} \mathrm{C}$.

\section{ASPECTOS MORFOLÓGICOS DAS INCLUSÓES FLUIDAS}

Estudos microscópicos detalhados das inclusóes fluidas das localidades anteriormente citadas, mostraram que elas apresentam formas e dimensóes variadas. As fotomicrografias de números 01 a 16 reúnem as principais feiçóes morfológicas observadas neste trabalho. Do ponto de vista morfológico, essas inclusóes foram classificadas em três padrōes distintos.

Padräo-I: fazem parte deste grupo as inclusōes fluidas alongadas, de contornos regulares, às vezes em forma de canalículos, com elongaçáo paralela, perpendicular ou inclinada em relaçáo ao eixo $\mathrm{c}$ do cristal hospedeiro. Suas dimensōes sấo bastante variáveis, estando o comprimento do maior eixo compreendido principalmente entre 4 e $160 \mu \mathrm{m}$, predominando as de tamanho intermediário a superior. Ocorrem dispersas através do cristal e/ou agrupadas em determinadas regióes, formando um ou mais núcleos de concentração (Fotomicrografias 01, 02, 03 e 04).

Padrăo-II: são inclusóes fluidas de contornos irregulares com orientaçốes e dimensóes semelhantes as anteriores, onde algumas das feiçōes observadas sugerem que sua forma atual seja resultante da dissoluçáo preferencial controlada por certas direçoes cristalográficas (essencialmente ao longo do eixo c e dos planos de clivagem). Destacam-se entre estas, as que possuem uma série de prolongamentos predominantemente orientados ao longo da direçăo do eixo $\mathbf{e}$ do topázio, e as que apresentam morfologias características, como as inclusōes em forma de pente ou com aspectos escalonados (Fotomicrografias 01, 04, 05, 06, 07, $08,09,10$ e 11). Em outras situaçóes, as inclusōes irregulares não possuem as feiçōes descritas acima, e ocorrem predominantemente de maneira aleatória, apresentando uma certa orientaçăo, em geral inclinadas em relaçăo ao eixo $\mathrm{c}$ do cristal (Fotomicrografia 02). Deve ser ainda ressaltado, que algumas inclusóes irregulares observadas apresentam feiçóes indicativas de escape de fluidos ("leakage") e de estrangulamento ("necking down"), sugerindo, portanto, a ocorrência de modificaçōes posteriores ao aprisionamento (Fotomicrografias 12, 13 e 14).

Padrāo-III: inclusōes fluidas de formas relativamente regulares, equidimensionais ou levemente alongadas, geralmente menores que as anteriores, com dimensóes médias de $10 \mu \mathrm{m}$, podendo ser inferiores a $4 \mu \mathrm{m}$. Ocorrem distribuídas ao longo de planos de cicatrização de fraturas, conchoidais ou náo, limitadas ao interior dos cristais, o que sugere tratar-se de inclusōes pseudo-secundárias (Fotomicrografias 05, 09, 15 e 16). 


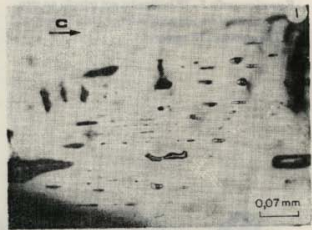

Fotomicrografis 2 - IF alongadas de contornos regulares, isoladas e paralelas ao eixo e do cristal. No canto inferior direito, inclusōes irregulares, distribuidas aleatoriamente.

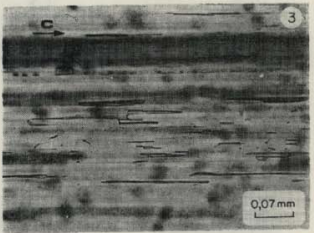

Fotomicrografia 4 - IF inclinadas ao lado de algumas perpendiculares a clivagem basal do topário.
Fotomicrografia 1 - Inclusdes fluidas (IF) alongadas, paralelas ao eixo c do topézio, com contornos predominantemente regulares, ao lado de algumas inclusōes irregulares.

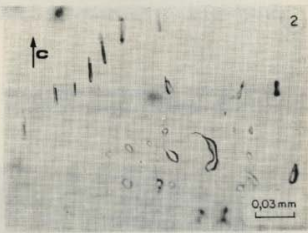

Fotomicrografia 3 - IF alongadas na forma de canalículos, paralelos ao eixo $\mathrm{c}$ do cristat.

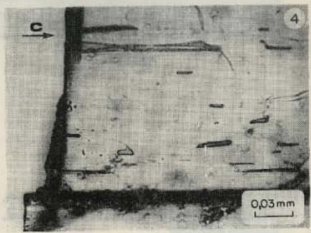




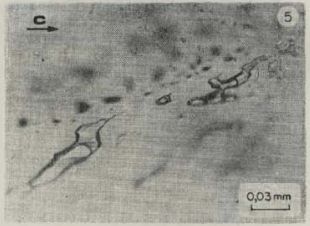

Fotomicrografia 6 - IF inclinadas em relaçato ao eixo e com bordas serrilhadas e alongadas na direçăo c.

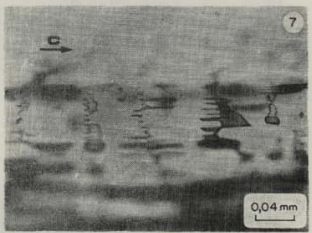

Fotomicrografis 8 - IF recortadas com prolongamentos perpendiculares à clivagem basal, sugerindo dissoluçæo.
Fotomicrografia S - IF inclinadas em relaçăo ao eixo c. Observa-se, em um nivel inferior, uma fratura de cicatrizaçío com IF menores.

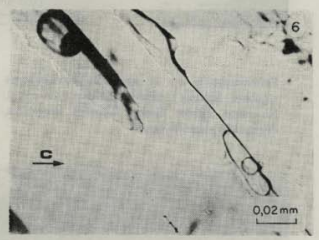

Fotomicrografia 7 - IF com prolongamentos paralelos ao eixo $c$ (forma de pente).

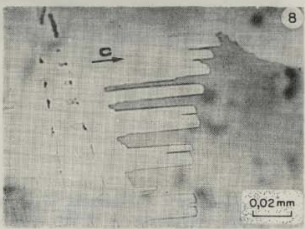




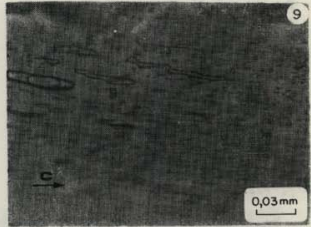

Fotomicrografia 10 - IF escalonada de contornos controlados pelas direçbes cristalográficas do topázio.

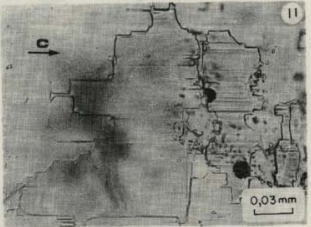

Fotomicrografia 12 - IF irregular e inclinada, mostrando feiçøes de escape de fluido (leakage).
Fotomicrografia 9 - IF escalonada inclinada em relaçăo ao eixo c. No nível inferior, fratura conchoidal de cicatrizaçato.

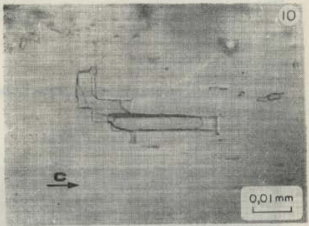

Fotomicrografia 11 - IF com evidencia de dissoluçăo preferencial segundo direģðes cristalográficas do topázio.

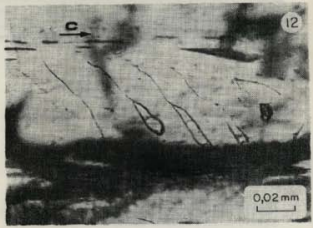




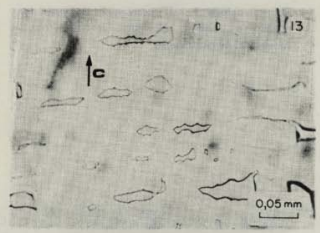

Fotomicrografia 14 - IF alongada com feiçōes típicas de estrangulamento (necking down).

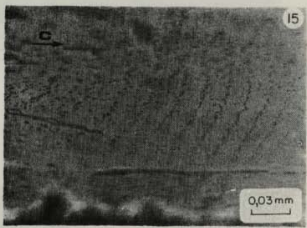

Fotomicrografia 16 - Fratura de cicatrizaçĭo de aspecto curvo, reunindo inclusổes de dimensōes variadas.
Fotomicrografia 13 - IF irregulares com feiçóes de estrangulamento (necking down).

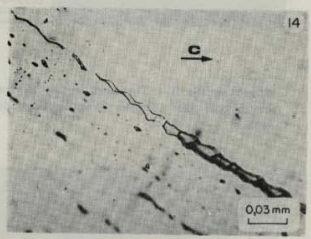

Fotomicrografia 15 -Fratura de cicatrizaçäo com uma sucessăo de niveis de IF pequenas e regulares.

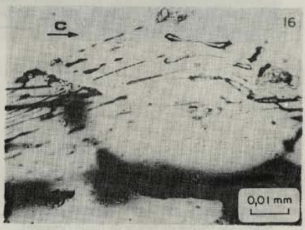




\section{DADOS MICROTERMOMETRICOS}

Com o objetivo de caracterizar as condigóes físico-químicas dos fluidos, importantes para 0 entendimento da natureza e da sequiència dos processos geológicos envolvidos (HOLLISTER \& CRAWFORD, 1981; WEISBROD et al, 1976; ROEDDER, 1984), foram realizadas várias determinaçóes microtermométricas de inclusóes fluidas selecionadas da jazida de Capão do Lana. A discussáo e a interpretaçáo detalhada desses dados, bem como de outros que ainda estão sendo obtidos, serão objetivo de futura publicação (GANDINI et al., em preparaçăo).

Ap6s serem devidamente caracterizadas e selecionadas, as inclusóes fluidas nāo portadoras de feiçōes indicativas de escape foram agrupadas, de acordo com a sua orientaçăo em relaçăo ao eixo c do cristal, em quatro tipos distintos, a saber:

irregulares);

- tipo-A:inclusōes fluidas paralelas ao eixo c (contornos regulares e

- tipo-B: inclusōes fluidas de contornos regulares e irregulares, inclinadas em relaçāo ao eixo c do topázio;

- tipo-C:inclusóes de contornos irregulares, dispostas de modo aleatório através do cristal;

- tipo-D:inclusōes distribuídas ao longo de planos de cicatrização de fraturas limitadas ao interior dos cristais.

Para cada um desses tipos, estudados separadamente, foram medidas as temperaturas de fusão (TI) e homogeneização (Th) das fases presentes, por meio da platina de resfriamento/aquecimento, e determinadas as composiçóes $\left(\mathrm{H}_{2} \mathrm{O}+\mathrm{CO}_{2}\right)$, salinidades (em equivalentes da porcentagem em peso de $\mathrm{NaCl}$ ), as densidades do $\mathrm{CO}_{2}\left(\mathrm{~d}_{\mathrm{CO}}\right)$ e as densidades totais das inclusóes $\left(d_{\text {total }}\right)$, com base nos trabalhos de NICHÓLLS \& CRAWFORD (1985) e COLLINS (1979). Os dados relativos a aproximadamente 400 inclusôes fluidas dos tipos A, B e C, pertencentes a 16 cristais distintos, encontram-se na Tabela 1.

As inclusōes do tipo-D apresentaram comportamentos semelhantes com relaçáo a $\mathrm{Tf}_{\mathrm{CO}_{2}}$ e Th $\mathrm{CO}_{2}$. Entretanto, os dados existentes ainda năo são suficientes para interpretaçóes mais precisas e serăo discutidos com mais detalhes em publicaçóes posteriores.

\section{DISCUSSŌES E CONCLUSŌES}

Pelos dados apresentados na Tabela 1, observa-se que as inclusōes fluidas dos vários tipos morfológicos de amostras de Capáo do Lana săo constituídas essencialmente por $\mathrm{CO}_{2}$ e $\mathrm{H}_{2} \mathrm{O}$, havendo apenas quantidades subordinadas de outros componentes voláteis dissolvidos na fase carbonica, responsáveis pelo ligeiro decréscimo nas $\mathrm{Tf}_{\mathrm{CO}_{2}}$. As salinidades das soluçóes aquosas, obtidas a partir das temperaturas de fusão de clatratos ( $\mathrm{Tf}_{\mathrm{C}}$ ), também săo bastante semelhantes, independentemente do tipo morfológico e das orientaçôes das 
Tabela 1 - Dados microtermometricos de inclusóes fluidas de topázios imperiais da jazida de Capão do Lana, Ouro Preto, MG.

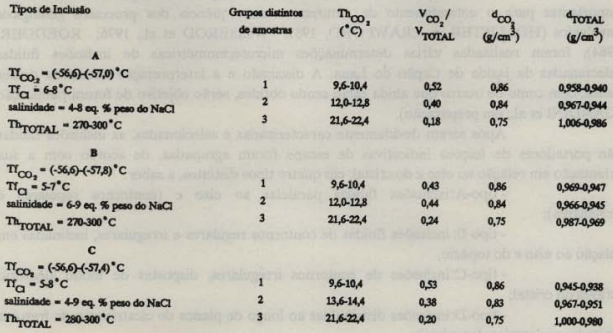

inclusōes. A sobreposiçáo dos valores das temperaturas de homogeneizaçáo total (Th total $\simeq 270^{\circ} \mathrm{C}-300^{\circ} \mathrm{C}$ ) mostra que as temperaturas de formaçáo dos diversos tipos de inclusáo foram as mesmas.

Foi constatado, ainda, que ocorrem variaçōes dos picos de maiores frequeancias de $T h \mathrm{CO}_{2}$ e das médias de $\mathrm{V}_{\mathrm{CO}_{2}} / \mathrm{V}_{\text {total }}$ (relaçōes volumétricas) em diferentes grupos de amostras, sendo que em um dado grupo esses valores variam de modo bem menos acentuado, quaisquer que sejam os tipos morfológicos e orientaçōes das inclusóes com relação ao eixo c. Esses fatos sugerem que em cada grupo de amostras o aprisionamento das inclusóes dos tipos A, B e C foi concomitante. Por outro lado, as variaçóes nos grupos distintos dăo margem às seguintes interpretaçóes: 1 - modificaçóes nas características dos fluidos, condicionadas às suas interaçóes com a rocha encaixante, portadora de quantidade variável de carbonatos; 2 - aprisionamento de inclusões fluidas em etapas de condiģóes distintas de P e T (inclusóes fluidas de várias geraçóes); 3 - evoluçáo do fluido associada a eventos póscristalizaçáo. Pelos estudos até agora realizados, a primeira hipotese mostra ser a mais razoável, uma vez que explicaria as diferenças nas proporçóes de $\mathrm{CO}_{2}$ por grupos de amostras e, conseqüentemente, nas suas respectivas densidades.

\section{AGRADECIMENTOS}


Os autores desejam expressar seus agradecimentos a TIMCIL (Topázio Imperial Mineraçăo, Comércio e Indústria Ltda.) pelas inúmeras amostras fornecidas; ao Sr. Flávio Machado de Souza Carvalho do IG/USP, pelo auxilio no tratamento dos dados microtermométricos; à Comissão Nacional de Energia Nuclear (CNEN) por permitir a obtençáo de algumas medidas de aquecimento; ao CNPq pelo auxilio prestado a um dos autores (Rosa Maria da Silveira Bello) através de Bolsa de Pesquisa (Proc. 303872/85-3) e, finalmente, aos Profs. José Vicente Valarelli do IG/USP e Júlio Cesar Mendes do DEGEO/EM/UFOP pela inestimável ajuda prestada em várias fases deste trabalho.

\section{REFERÊNCIAS BIBLIOGRÁFICAS}

CASSEDANNE, J.P. (1989) Famous minerals locaties: the Ouro Preto topaz mines. The Mineralogical Record. 20(3): 221-233.

COLUINS, P.L.F. (1979) Gas hydrates in $\mathrm{CO}_{2}$-bearing fluids and the use freezing data form estimation of salinity. Economic Geology, 74(6): 1435-1444.

FBRREIRA, C.M. (1983) Vulcanismo ácido no Quadrilatero Ferrífero e sua relaçăo com algumas ocorrências e/ou depósitos minerais. In: SIMPÓSIO DE GEOLOGIA DE MINAS GERAIS, 2., Belo Horizonte, 1983. Anais. Belo Horizonte, SBG. Boletim 3, p.128-133.

FERREIRA, C.M. (1987) Geologia da jazida de topázio do Morro de Saramenha. REM Revista da Escola de Minas, 40(3):15-17.

FERREIRA, C.M. - Topázio de Ouro Preto: principais características geologicas das ocorrências. In: Brasil. Departamento Nacional da Produçăo Mineral. Principais depósitos minerais do Brasil. Brasilia, DNPM. v. 4 (no prelo).

FUZIKAWA, K. (1985) Inclusōes fluidas: métodos usuais de estudo e aplicaçōes. In: Contribuigües à Geologia e Petrologia. Belo Horizonte, SBG/CBMM, p. 29-44.

GANDINI, A.L.; SVISERO, D.P.; BELLO, R.M.S.; CARVALHO, F.M.S.; VALARELLI, J.V. (1990) Inclusōes fluidas de topázios imperiais das jazidas de Capão do Lana e Caxambu, Ouro Preto, MG. In: CONGRESSO BRASILEIRO DE GEOLOGIA, 36., Natal, 1990. Boletim de Resumos. Natal, SBG, p. 227-228.

GORCEIX, H. (1881) Estudo geológico das jazidas de topázio da Província de Minas Gerais, Brasil. Anais da Escola de Minas de Ouro Preto, 1:15-18. 
HOLLISTER, L.S. (1981) Information intrinsically available from fluid inclusions. In: HOLLISTER, L.S. \& CRAWFORD, M.L. (eds.) Fluid Inclusions: applications to petrology. Calgary, Mineralogical Association of Canada, p. 1-12. (Short course handbook, v.6).

HOLLISTER, L.S. \& CRAWFORD, M.L. (1981) Fluid Inclusions: applications to petrology. Calgary, Mineralogical Association of Canada. 304p. (Short course handbook, v.6).

KELLER, P.C. (1983) The Capáo topaz deposits, Ouro Preto, Minas Gerais, Brazil. Gems \& Gemology, 19(1): 12-20.

NICHOLLS, J. \& CRAWFORD, M.L. (1985) Fortran Programs for calculation of fluid properties from microthermometric data on fluid inclusions. Geochimica et Cosmochimica Acta, 11(5): 614-645.

OLSEN, D.R. (1971) Origin of topaz deposits near Ouro Preto, Minas Gerais, Brazil. Economic Geology, 66(4): 627-631.

PIRES, F.R.M. (1983) Geologia e gênese dos depósitos de topázio do Distrito de Ouro Preto, Minas Gerais. In: SIMPÓSIO DE GEOLOGIA DE MINAS GERAIS, 2., Belo Horizonte, 1983. Anais. Belo Horizonte, SBG. Boletim 3, p. 283-296.

POTY, B.; LEROY, J.; JACHIMOWICZ, L. (1976) Un nouvel appareil pour la mesure des températures sous le microscope: l'installation de microthermométrie Chaixmeca. Bulletin de la Société Française de Minéralogie et de Cristallographie, 99(2/3): 182-186.

ROEDDER, E. (1984) Fluid inclusions. Reviews in Mineralogy, 12:1-644.

SORBY, H.C. (1858) On the microscopic structure of crystals, indicating the origin of mineral and rocks. The Quartely Journal of the Geological Society of London, 14(1): 453-500.

WEISBROD, A.; POTY, B; TOURET, J. (1976) Les inclusions fluides in géochimiepetrologie: tendances actuelles. Bulletin de la Société Française de Minéralogie et de Cristallographie, 99(2/3): 140-152. 